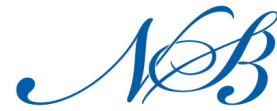

Notulae Scientia Biologicae

\title{
Propagation of Iranian Cornelian Cherry (Cornus mas L.) by Rooted Stem Cuttings
}

\author{
Hamid HASSANPOUR ${ }^{1 *}$, Mohamad ALI SHIRI ${ }^{2}$ \\ ${ }^{1}$ Urmia University, Faculty of Agriculture, Department of Horticulture, Urmia, Iran \\ ${ }^{2}$ The University of Guilan, Faculty of Agriculture, Department of Horticulture, Rasht, Iran; phhassanpour@gmail.com (*corresponding author)
}

\begin{abstract}
Clonal propagation of Cornelian cherry (Cornus mas L.) from cuttings will permit nursery production of cloned Cornelian cherry and encourage selection of superior genotypes. The effects of indole-3-butyric acid (IBA) concentrations, five genotypes and two types of media on root performance of Cornelian cherry cuttings were investigated. The percentage of rooted cuttings, mean root length, average root number per cutting, root fresh weight and root dry weight were recorded after three months. Orthogonal contrasts were used to test the effects of the auxin treatments. Regression analysis for determination of appropriate equation was performed. The IBA treatment increased the rooting percentage in genotype $\mathrm{C} 1, \mathrm{C} 3$ and $\mathrm{C} 4$ but did not affect that of genotype $\mathrm{C} 2$ and $\mathrm{C} 5$. The maximum rooting percentage, mean root length, average root number per cutting, root fresh weight and root dry weight was obtained for C3 genotype and in sand media. No statistically significant correlation was observed between callusing and other measured parameters but the rest of parameters correlate statistically with rooting. According to the regression results, it was clear that the pattern of quadratic function was better than other models for rooting. The highest rooting percentage was obtained from C3 genotype. Therefore, clonal production of this genotype is practical.
\end{abstract}

Keywords: cherry, correlation, IBA, regression, rooting

\section{Introduction}

Cornus (belonging to the Cornaceae family) is a very large genus which comprises forty species of shrubs and trees native to Central and Southern Europe and parts of Western Asia. Many Cornus species are used as ornamentals, but only a few are grown for their edible fruits; chief among these is the Cornelian cherry (Cornus mas L.) (Brindza et al., 2007; Ercisli, 2004). The fruits usually have a sweet-sour taste. They contain twice as much vitamin $\mathrm{C}$ as oranges on a fresh weight basis (Hassanpour et al., 2011).

In Iran, Cornelian cherry trees are spread in west parts of the country (East Azerbaijan and Qazvin provinces) (Hassanpour et al., 2013). Cornelian cherry is generally propagated by seed. The major shortcoming of this method is its heterozygoty (Hassanpour et al., 2012). Therefore, selection of valuable genotypes of Cornelian cherry and clonal propagation of those through cuttings are required. There are no reports of vegetative propagation of Cornelian cherry through cuttings in Iran.

There are great differences in the rooting potential among plant species; in particular, tree species are often categorized into groups, easy, moderate and hard-to-root species (Denaxa et al., 2012). In some plant species, root formation initiates without the use of rooting or growth promoting substances, while in others it requires the application of growth regulators, usually auxins (Contessa et al., 2011). Many plant and environmental factors, including genotypes, nutritional status, phenological stage and environmental conditions determine seasonal variations in rooting ability of woody cuttings (Hartmann et al., 1990; Sebastiani and Tognetti, 2004). Adventitious root formation can be stimulated by auxins, but their role in rooting is not exclusive and other compounds are involved also (Gaspar et al., 1997). Indole butyric acid (IBA) is widely used because it is non toxic to most plants over a wide range and promotes root growth in a large number of plant species (Noor et al., 2009). Literature has been widely reported that treating stem cuttings with different hormone concentrations before planting in a suitable rooting medium is required for effective rooting (Agele et al., 2013; Contessa and Valentini, 2011).

Rooting media can also affect the rooting of cuttings. Apart from holding the cutting in place, the medium has to provide the correct degree of moisture to the cutting base, whilst permitting aeration (Hartmann et al., 2010). Prior research with other tree species has shown that genotype (Almehdi et al., 2002; Yazici et al., 2009), IBA concentration (Al Barazi and Schwabe, 1982), and media (Prat et al., 1998) are variables that affect rooting percentage, and consequently were evaluated in the present study. According to our previous study, these genotypes 
have high antioxidant and nutritional value (Hassanpour et al., 2011). Therefore, the aim of the present study was to investigate the effect of rooting media and the use of IBA on the rooting ability of five genotypes of Iranian Cornelian cherry.

\section{Materials and methods}

Hardwood dormant cuttings of Cornelian cherry were prepared from vigorous shoots of 15 -yr-old plants during November 2013. Each cutting was immersed in fungicide solution for a few minutes $(0.1 \%$ benomyl). The basal ends of the cuttings were dipped into IBA solutions at 0, 2000 and $4000 \mathrm{ppm}$ for 5 seconds. Cuttings placed in water served as controls. After treatment, they were planted directly in two different rooting media (sand and perlite : sand $(1: 1 \mathrm{v} / \mathrm{v}))$ in greenhouse.

A full factorial experimental design involving 30 treatments ( 5 genotypes named $\mathrm{C} 1$ to $\mathrm{C} 5$, sand vs. sand : perlite $(1: 1 \mathrm{v} / \mathrm{v})$ and no auxin vs. $2000 \mathrm{ppm}$ IBA vs. 4000 ppm IBA, i.e. $5 \times 2 \times 3=30$ ) was performed on Cornelian cherry. Four replicates of 24 cuttings were randomly assigned per treatment. After a rooting period of 90 days, rooting and callusing rates, mean root length, average root number per cutting, root fresh weight and root dry weight were recorded.

The results were analyzed using GLM procedures (Statistical Analysis Systems Institute 1985) for a factorial design. The variance of percentage data was not homogeneous, so rooting and callusing values were transformed according to the angular transformation arcsin $\sqrt{x}$. Orthogonal contrasts were used to test the effects of the auxin treatments. Correlation and regression analysis of the results were performed in SPSS (Software Version 16 SPSS).

\section{Results and discussion}

The effect of the genotype of Cornus mas, rooting media and auxin treatment on rooting and callusing percentage, mean root length, average root number per cutting, root fresh weight and root dry weight of $C$. mas cuttings have been shown in Tab. 1. Rooting-response varied with genotypes (Tab. 1). Among the six detected rooting characters, percent callusing and mean root length did not show significant difference among genotypes, but the differences of the rest parameters were significant. Also, orthogonal contrasts for the effects of the auxin treatments have been shown in Tab. 1.

The genotype of $C$. mas affect rooting and callusing percentage, mean root length, average root number per cutting, root fresh weight and root dry weight. The C3 genotype showed a greater rooting and callusing percentage, average root number per cutting, root fresh weight and root dry weight than other genotypes $(59.17 \%, 5.75 \%, 3.63$, $14.17 \mathrm{~g}$ and $8.01 \mathrm{~g}$ respectively).

Rooting media had little effect on rooting success (Tab. 1). Higher rooting occurred for cuttings in sand (30\%) compared to sand:perlite (1:1) (27.5\%), but the results were not significant. There were no significant differences between the two types of media on all of the measured parameters (sand and sand:perlite (1:1)).

There was no significant interaction between media and IBA concentrations. There was significant interaction between genotype and IBA concentrations for all parameters except for callusing and mean root length. Also, there was no significant interaction between genotype, media and IBA concentrations for all parameters accept for percentage of rooting $(\mathrm{P}=0.0001)$. Auxin application, irrespective of dose, was associated with increased rooting ( $47.5 \%$ vs. $0 \%)$, mean root length $(4.66 \mathrm{~mm}$ vs. $0 \mathrm{~mm})$, root fresh weight $(7.85 \mathrm{~g}$ vs. $0 \mathrm{~g})$ and root dry weight $(3.9 \mathrm{~g}$ vs. 0 g) and callusing percentage $(0.25 \%$ vs. $4.75 \%)$ compared to the control treatment (Tab. 1$)$.

The correlations between measured parameters in cuttings are shown in Tab. 2. No statistically significant correlation was observed between callusing and other measured parameters but the rest of parameters correlate statistically with rooting (Tab. 2). So, there was no association between rooting and callusing in Cornelian cherry cutting.

The regression analysis results are shown in Tab. 3 . According to the regression results, it was clear that the pattern of quadratic function with $\mathrm{R}^{2}=0.762$ and significance level of regression $(\mathrm{P}=0.000)$, was better than the other models for rooting.

The equation is as follow:

Rooting $=-43.750+56.875($ IBA $)-13.125(\text { IBA })^{2}$

Genotype effects on rooting of Cornelian cherry cuttings were consistent with the results reported by Yazici et al. (2009) and Almehdi et al. (2002) with almond and pistachio, respectively. Therefore, selection of source genotypes with a high propensity for rooting, as well as for other favorable characters (e.g. disease resistance) is very important for successful commercial production. Among the genotypes, the rooting percentage of cuttings was highest in $\mathrm{C} 3$ and least in $\mathrm{C} 2$ and $\mathrm{C} 5$ genotypes. This response can be attributed to differences in the genotypes ability to root via stem cutting propagation.

One of the most important criteria for the successful rooting of cuttings is a suitable rooting media. Rooting percent in sand:perlite (1:1) media was low. It is likely that excessive water is retained by this media causing damage to the base of the cuttings (Prat et al., 1998). Therefore, one major difference between these media is their water holding capacity and consequently their air: water ratio.

The application of auxin to attract assimilates to the cutting base and to stimulate the meristematic differentiation is probably the best known mean of promoting rooting in all kind of cuttings. However, tree species vary considerably in the optimal application (Tchoundjeu et al., 2002). The present study showed that application of auxin significantly improved rooting traits for Cornelian cherry cuttings. The same results have been reported on many plants capable of rooting (Sharma and Aier, 1989). Successful rooting is determined not only by rooting percentage, but also by the number of roots formed (Hartmann et al., 1990; Sebastiani and Tognetti, 2004). $2000 \mathrm{mg} / \mathrm{l} \mathrm{IBA}$ produced the best rooting traits and hence it was recommended for $C$. mas cutting. Higher concentrations of auxin did not substantially produce a better rooting result. In the present study, cuttings pretreated with $4000 \mathrm{mg} / \mathrm{l}$ IBA rooted worse than those 
194

pretreated with $2000 \mathrm{mg} / \mathrm{l}$ IBA. The inhibitory effect caused by high exogenous auxin also occurred in other plants such as peach (Tworkoski and Takeda, 2008).

Rooting was considerably stimulated by the auxin treatment. The ability of auxins to stimulate cutting root formation is well known (Davis et al., 1988; Hartmann and Kester, 1983). Moreover, IBA is the auxin which is most widely used in commercial rooting (Nickell, 1982). The application of a 2000 or $4000 \mathrm{mg} / \mathrm{l}$ solution of IBA to $C$. mas cuttings was effective in the promotion of rooting. The increase in root number induced by the application of IBA has also been reported by other authors (Aminah et al., 1995; Wiesman and Lavee, 1995).

In this study, no statistically significant correlation was observed between rooting percentage and callusing percentage of cutting $(-0.11)$. Furthermore, low significant relationships were found between rooting percentage of cuttings and mean root length (Tab. 2). The regression results showed that quadratic function could be the best model for rooting of Cornelian cherry cutting.

\section{Conclusions}

As a conclusion, the application of IBA at a concentration of $2000 \mathrm{ppm}$ seemed to be the best application for rooting of cuttings of Cornelian cherry. There was no variation among the different media in terms of rooting percentage. However, apart from IBA and rooting media, other factors such as temperature of rooting media, cutting type should be taken into consideration.

Tab. 1. Mean values of rooting response of Cornus mas cuttings

\begin{tabular}{|c|c|c|c|c|c|c|}
\hline & $\begin{array}{c}\text { Rooting } \\
(\%)\end{array}$ & $\begin{array}{c}\text { Callusing } \\
(\%)\end{array}$ & $\begin{array}{c}\text { Mean root } \\
\text { length } \\
(\mathrm{mm})\end{array}$ & $\begin{array}{c}\text { Average root } \\
\text { number per } \\
\text { cutting }\end{array}$ & $\begin{array}{l}\text { Root fresh } \\
\text { weight }(\mathrm{g})\end{array}$ & $\begin{array}{c}\text { Root dry } \\
\text { weight }(g)\end{array}$ \\
\hline \multicolumn{7}{|l|}{ Genotype } \\
\hline $\mathrm{C} 1$ & $38.33^{\mathrm{b}}$ & 0.072 & 5.43 & $0.75^{b}$ & $4.17^{b}$ & $1.17^{\mathrm{b}}$ \\
\hline $\mathrm{C} 2$ & $0^{\mathrm{b}}$ & 1.67 & 0 & $0^{\mathrm{b}}$ & $0^{\mathrm{b}}$ & $0^{\mathrm{b}}$ \\
\hline C3 & $59.17^{a}$ & 5.75 & 3.74 & $3.63^{\mathrm{a}}$ & $14.17^{\mathrm{a}}$ & $8.01^{\mathrm{a}}$ \\
\hline $\mathrm{C} 4$ & $36.25 b$ & 0.072 & 0.55 & $0.43^{\mathrm{b}}$ & $3.83^{b}$ & $1.13^{\mathrm{b}}$ \\
\hline $\mathrm{C} 5$ & $\mathrm{ob}$ & 4.08 & 0 & $0^{\mathrm{b}}$ & $0^{\mathrm{b}}$ & $0^{\mathrm{b}}$ \\
\hline \multicolumn{7}{|l|}{ Media } \\
\hline Sand & 30 & 0.83 & 0.48 & 0.53 & 4.48 & 1.16 \\
\hline Sand:perlite (1:1) & 27.5 & 2.5 & 3.89 & 0.75 & 5.98 & 1.53 \\
\hline \multicolumn{7}{|l|}{$\mathrm{T}$} \\
\hline 0 & $0^{c}$ & $4.75^{\mathrm{a}}$ & 0 & $0^{\mathrm{b}}$ & $0^{c}$ & $0^{\mathrm{b}}$ \\
\hline 2000 & $47.5^{\mathrm{a}}$ & $0.25^{b}$ & 4.66 & $0.9^{\mathrm{a}}$ & $7.85^{\mathrm{a}}$ & $3.9^{\mathrm{a}}$ \\
\hline 4000 & $38.75^{\mathrm{b}}$ & $0^{\mathrm{b}}$ & 1.59 & $0.33^{\mathrm{b}}$ & $5.85^{\mathrm{b}}$ & $3.53^{\mathrm{a}}$ \\
\hline \multicolumn{7}{|l|}{ Level of significance } \\
\hline Genotype (G) & 0.0001 & 0.5145 & 0.2344 & 0.0000 & 0.0001 & 0.0001 \\
\hline $\operatorname{Media}(\mathrm{M})$ & 0.1411 & 0.2248 & 0.1568 & 0.1811 & 0.1973 & 0.3462 \\
\hline IBA (I) & 0.0001 & 0.0009 & 0.1341 & 0.0001 & 0.0003 & 0.0002 \\
\hline $\mathrm{G}^{*} \mathrm{M}$ & 0.0019 & 0.7732 & 0.2436 & 0.2742 & 0.1119 & 0.1368 \\
\hline $\mathrm{M}^{*} \mathrm{I}$ & 0.4824 & 0.3404 & 0.2324 & 0.3351 & 0.6249 & 0.6906 \\
\hline $\mathrm{G}^{*} \mathrm{I}$ & 0.0001 & 0.5475 & 0.1748 & 0.0000 & 0.0001 & 0.0001 \\
\hline $\mathrm{G}^{*} \mathrm{M}^{*} \mathrm{I}$ & 0.0001 & 0.9280 & 0.1644 & 0.2061 & 0.1768 & 0.0481 \\
\hline \multicolumn{7}{|l|}{ Contrasts } \\
\hline Control vs. IBA2000 & 0.000 & 0.010 & 0.070 & 0.026 & 0.070 & 0.032 \\
\hline Control vs. IBA4000 & 0.030 & 0.007 & 0.685 & 0.013 & 0.006 & 0.008 \\
\hline IBA 2000 vs. IBA 4000 & 0.030 & 0.884 & 0.158 & 0.027 & 0.044 & 0.600 \\
\hline
\end{tabular}

Note: Means in each column followed by similar letters are not significantly different at $5 \%$ level

Tab. 2. Pearson's correlation coefficients for quantitative determinations in rooting of Cornelian cherry (Cornus mas L.)

\begin{tabular}{|c|c|c|c|c|c|c|}
\hline Variables & $\mathrm{R}$ & $\mathrm{C}$ & MRL & ARNC & FFW & RDW \\
\hline Rooting $(\mathrm{R})$ & 1 & $-0.11^{\mathrm{ns}}$ & $0.36^{*}$ & $0.76^{* *}$ & $0.73^{* *}$ & $0.77^{* *}$ \\
\hline Callusing (C) & & 1 & $-0.04^{\mathrm{ns}}$ & $-0.08^{\mathrm{ns}}$ & $-0.08^{\mathrm{ns}}$ & $-0.09^{\mathrm{ns}}$ \\
\hline Mean root length (MRL) & & & 1 & $0.46^{*}$ & $0.39^{*}$ & $0.41^{*}$ \\
\hline Average root number per cutting (ARNC) & & & & 1 & $0.90^{* *}$ & $0.92^{* *}$ \\
\hline Root fresh weight (RFW) & & & & & 1 & $0.97^{* *}$ \\
\hline Root dry weight (RDW) & & & & & & 1 \\
\hline
\end{tabular}

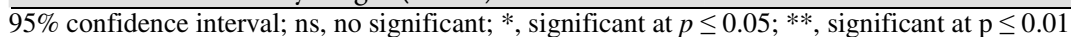


Tab. 3. Coefficients of regression on rooting of Cornelian cherry (Cornus mas L.) cuttings using IBA

\begin{tabular}{|c|c|c|c|c|c|}
\hline & \multicolumn{2}{|c|}{$\begin{array}{c}\text { Unstandardized } \\
\text { Coefficients }\end{array}$} & \multirow{2}{*}{$\begin{array}{c}\begin{array}{c}\text { Standardized } \\
\text { Coefficients }\end{array} \\
\text { Beta }\end{array}$} & \multirow[b]{2}{*}{$\mathrm{t}$} & \multirow[b]{2}{*}{ Sig. } \\
\hline & B & $\begin{array}{l}\text { Std. } \\
\text { Error }\end{array}$ & & & \\
\hline IBA & 56.875 & 13.953 & 2.444 & 4.076 & 0.000 \\
\hline $\begin{array}{c}\mathrm{IBA}^{* *} \\
2\end{array}$ & -13.125 & 12.287 & -2.280 & -3.802 & 0.000 \\
\hline $\begin{array}{l}\text { (Const } \\
\text { ant) }\end{array}$ & -43.750 & 3.452 & & -3.561 & 0.001 \\
\hline \multicolumn{2}{|c|}{ Adjusted R } & & 0.762 & & \\
\hline
\end{tabular}

\section{References}

Agele SO, Aiyelari OP, Obi EA (2013). Pattern of rooting and growth of cuttings of some species of insecticidal and medicinal importance as affected by growth promoting substances. Octa J Environ Res 1(2):151-160.

Al-Barazi Z, Schwabe WW (1982). Rooting softwood cuttings of adult Pistacia vera. J Hortic Sci 57:247-252.

Almehdi AA, Parfitt DE, Chan H (2002). Propagation of pistachio rootstock by rooted stem cuttings. Sci Hortic (Amsterdam) 96:359-363.

Aminah H, Dick JMcP, Leakey RRB, Grace J, Smith RI (1995). Effect of indole butyric acid (IBA) on stem cuttings of Shorea leprosula. Forest Ecol Manag 72:199-206.

Brindza P, Brindza J, Toth D, Klimenko SV, Grigorieva O (2007). Slovakian Cornelian cherry (Cornus mas L.): potential for cultivation. Acta Hort 760:433-437.

Contessa C, Valentini N (2011). Decreasing the concentrations of IBA or combination with ethylene inhibitors improved bud retention in semi-hard wood cuttings of hazelnut cultivar Tonda Gentile delle Langhe. Sci Hortic (Amsterdam) 131:103-106.

Davis TD, Haissig N, Sankhla N (1988). Adventitious root formation in cuttings. Advances in Plant Sciences Series, vol. 2. Dioscorides Press, Portland, OR. 315 p.

Denaxa NK, Vemmos SN, Roussos PA (2012). The role of endogenous carbohydrates and seasonal variation on rooting ability of cuttings of an easy and a hard to root olive cultivars. Sci Hortic (Amsterdam) 143:19-28.

Ercisli S (2004). Cornelian cherry germplasm resources of Turkey. J Fruit Ornam Plant Res 12:87-92.

Gaspar T, Kevers C, Hausman JF (1997). Indissociable chief factors in the inductive phase of adventitious rooting. In: Altman, A., Waisel, Y. (Eds.), Biology of Root Formation and Development. Plenum Press, New York, pp. 55-63.

Hartmann HT, Kester DE (1983). Plant Propagation: Principles and Practices. Prentice-Hall International, London, 727 p.
Hartmann HT, Kester DE Davies Jr FT (1990). Plant Propagation. Principles and Practices, 5th ed. Prentice-Hall, New Jersey.

Hartmann HT, Kester DE, Davies Jr FT, Geneve RL (2010). Plant Propagation: Principles and Practices, $8^{\text {th }}$ ed. Prentice Hall, New Jersey, USA. pp. 363-365.

Hassanpour H, Hamidoghli Y, Hajilo J, Adlipour M (2011). Antioxidant capacity and phytochemical properties of Cornelian cherry (Cornus mas L.) genotypes in Iran. Sci Hortic (Amsterdam) 129:459-463.

Hassanpour H, Hamidoghli Y, Samizadeh H (2012). Some fruit characteristics of Iranian Cornelian cherries (Cornus mas L.). Not Bot Horti Agrobo 40(1):247-252.

Hassanpour H, Hamidoghli Y, Samizadeh H (2013). Estimation of genetic diversity in some Iranian Cornelian cherries (Cornus mas L.) accessions using ISSR markers. Biochem Syst Ecol 48:257-262.

Nickell LG (1982). Plant growth regulators. Agricultural Uses. Springer, New York, pp. 4-5.

Noor Camellia NA, Thohirah LA, Abdullah NAP, Mohd Khidir O (2009). Improvement on rooting quality of Jatropha curcas using indole butyric acid (IBA). Res J Agr Biol Sci 5(4):338343.

Prat L, Botti C, Palzkill D (1998). Rooting of jojoba cuttings: the effect of clone, substrate composition and temperature. Ind Crop Prod 9:47-52.

Sebastiani L, Tognetti R (2004). Growing season and hydrogen peroxide affects on root induction and development in Olea europaea L. (cvs 'Frantoio' and 'Gentile di Larino') cuttings. Sci Hortic (Amsterdam) 100:75-82.

Sharma SD, Aier NB (1989). Seasonal rooting behaviour of cuttings of plum cultivars as influenced by IBA treatments. Sci Hortic (Amsterdam) 40:297-303.

Statistical Analysis Systems Institute (1985). SAS User's Guide: Statistics, ver. 5. SAS Institute Inc, Cary, NC.

Tchoundjeu Avana ZML, Leakey RRB, Simons AJ, Asaahl E, Duguma B, Bell JM (2002). Vegetative propagation of Prunus africana: effects of rooting medium, auxin concentrations and leaf area. Agroforest Syst 54:183-192.

Tworkoski T, Takeda F (2008). Rooting response of shoot cuttings from three peach growth habits. Sci Hortic (Amsterdam) 115:98-100.

Wiesman Z, Lavee S (1995). Enhancement of IBA stimulatory effect on rooting of olive cultivar stem cuttings. Sci Hortic (Amsterdam) 62:189-198.

Yazici K, Dal B, Gozlekci S, Kaynak L, Ersoy N (2009). Effects of cutting type and duration on rooting of three cherry laurel (Prunus laurocerasus L.) genotypes. Acta Hort 818:199-204. 